\title{
PEMERIKSAAN MPN Coliform DAN Colitinja PADA MINUMAN ES TEH YANG DIJUAL DI PELABUHAN RAMBANG KOTA PALANGKA RAYA
}

\author{
Nur Fuji Annisa \\ Mahasiswa Program Studi D-III Farmasi Fakultas IImu Kesehatan \\ Universitas Muhammadiyah Palangkaraya \\ Email: nurfujiannisa15@gmail.com
}

\begin{abstract}
Abstrak
Menurut Undang-Undang Republik Indonesia Nomor 36 Tahun 2009 tentang Kesehatan, yang dimaksud dengan upaya kesehatan adalah setiap kegiatan dan/atau serangkaian kegiatan yang dilakukan secara terpadu, terintregasi dan berkesinambungan untuk memelihara dan meningkatkan derajat kesehatan masyarakat dalam bentuk pencegahan penyakit, peningkatan kesehatan, pengobatan penyakit, dan pemulihan kesehatan oleh pemerintah dan/atau masyarakat.

Minuman es teh merupakan minuman yang digemari konsumen rumah makan karena harganya terjangkau dan dapat dijadikan pendamping makanan. Minuman es teh dibuat dengan menggunakan air dan es yang merupakan salah satu sumber kontaminasi bakteri Coliform. Faktor-faktor yang mempengaruhi kontaminasi bakteri Coliform dan Colitinja pada minuman es teh adalah air yang digunakan untuk membuat es teh, dan es yang digunakan karena tidak diketahui apakah air yang digunakan adalah air yang sudah dimasak atau bukan. Tujuan penelitian ini adalah untuk mengetahui pencemaran bakteri Coliform dan Coli tinja dan kelayakan air minum yang terdapat pada es teh yang dijual di Pelabuhan Rambang Kota Palangka Raya dengan menggunakan metode MostProbable Number (MPN).

MPN adalah metode pemeriksaan air yang dilakukan untuk mengetahui kontaminasi akibat bakteri Coliform dan Coli tinja. Pengujian dilakukan dengan menggunakan ragam I (7 tabung). Pengamatan sampel yang positif dapat dilihat dengan mengamati adanya kekeruhan dan gelembung gas pada tabung durham.

Hasil penelitian yang dilakukan setelah melalui tahap uji praduga dan uji penegasan didapatkan hasilnya yaitu 6 sampel yang diteliti positif mengandung bakteri Coliform dan Coli tinja, sampel yang positif bisa dilihat dari adanya kekeruhan dan gelembung gas pada tabung durham yang ada pada tabung reaksi. Didapatkan hasil positif dengan nilai MPN nya 240/100 $\mathrm{ml}$. hal ini menandakan bahwa 6 sampel minuman es teh yang diuji tidak layak untuk dikonsumsi oleh masyarakat karena menunjukkan hasil positif mengandung bakteri Coliform dan Coli tinja. Dari hasil kedua suhu tersebut dapat disimpulkan bahwa keenam sampel es teh mengandung bakteri Coliform dan Coli tinja. Sesuai standar baku mutu air minum Menteri Kesehatan Republik Indonesia Nomor 492 Tahun 2010, pada parameter mikrobiologi untuk bakteri Coliform dan Coli tinja kadar maksimum pada air minum yang diperbolehkan ialah $0 / 100 \mathrm{ml}$ sampel. Keenam sampel es teh yang positif tersebut tidak layak untuk dikonsumsi masyarakat.
\end{abstract}

Kata Kunci : Es teh, Coliform, Coli Tinja dan Most Probable Number (MPN). 


\section{PENDAHULUAN}

Kesehatan merupakan suatu hal yang sangat penting bagi manusia, Undang-Undang Kesehatan Republik Indonesia Nomor 36 Tahun 2009 memberi batasan tentang kesehatan yaitu, kesehatan adalah keadaan sehat, baik secara fisik, mental, spiritual, maupun sosial yang memungkinkan setiap orang untuk hidup produktif secara sosial dan ekonomis. Menurut Undang-Undang Republik Indonesia Nomor 36 Tahun 2009 tentang Kesehatan, yang dimaksud dengan upaya kesehatan adalah setiap kegiatan dan/atau serangkaian kegiatan yang dilakukan secara terpadu, terintregasi dan berkesinambungan untuk memelihara dan meningkatkan derajat kesehatan masyarakat dalam bentuk pencegahan penyakit, peningkatan kesehatan, pengobatan penyakit, dan pemulihan kesehatan oleh pemerintah dan/atau masyarakat.

Menurut Departemen Kesehatan Republik Indonesia Tahun 1993 tentang Pedoman Pelatihan Teknisi Laboratorium Pemeriksaan Bakteriologis Air, air minum yang ideal seharusnya jernih, tidak berwarna, tidak berasa dan tidak berbau. Air minum pun seharusnya tidak mengandung kuman patogen dan segala bentuk makhluk yang membahayakan kesehatan manusia, tidak mengandung zat kimia yang dapat mengubah fungsi tubuh, dan dapat merugikan secara ekonomis.

Bagi ahli kebersihan air minum, tidak semua jasad renik di dalam air penting, tetapi hanya sekelompok kuman tergolong penting seperti : kuman-kuman Coliform, yaitu kuman yang tumbuh cepat dan terdapat dalam kotoran manusia. Penyakit-penyakit utama yang ditularkan lewat air ialah : disentri, kolera dan tifoid. Penyakit tersebut adalah penyakit usus sehingga kuman-kuman penyebabnya terdapat dalam tinja manusia. Untuk menentukan apakah air dapat diminum atau tidak, haruslah dipenuhi syarat-syarat fisik, kimia dan bakteriologik. Syarat bakteriologik ialah bahwa air tersebut tidak mengandung kuman Coliform (Misnadiarly dan Djajaningrat, 2014).

Menurut Peraturan Menteri Kesehatan Republik Indonesia Nomor : 492/MENKES/PER/IV/2010, tentang Persyaratan Kualitas Air Minum, yang dimaksud air minum adalah air yang melalui proses pengolahan atau tanpa proses pengolahan yang memenuhi syarat kesehatan dan dapat langsung diminum. Air minum aman bagi kesehatan apabila memenuhi persyaratan fisika, mikrobiologis, kimiawi, dan radioaktif, dengan jumlah bakteri Coliform adalah 0 MPN/100 ml.

Bakteri Coliform merupakan suatu grup bakteri yang digunakan sebagai 
indikator adanya polusi kotoran dan kondisi sanitasi yang tidak baik terhadap air, makanan, susu dan produk-produk susu. Adanya bakteri Coliform di dalam makanan atau minuman menunjukkan kemungkinan adanya mikroorganisme yang bersifat enteropatogenik dan/atau toksigenik yang berbahaya bagi kesehatan. Bakteri Coliform dapat dibedakan atas dua grup yaitu: (1) Coliform fekal, misalnya Escherichia coli, dan (2)Coliform non-fekal, misalnya Enterobacter aerogenes. Escherichia coli merupakan bakteri yang berasal dari kotoran hewan maupun manusia, sedangkan Enterobacter aerogenes biasanya ditemukan pada hewan atau tanaman-tanaman yang telah mati (Irianto, 2013).

Minuman es teh merupakan minuman yang digemari konsumen rumah makan karena harganya terjangkau dan dapat dijadikan pendamping makanan. Minuman es teh dibuat dengan menggunakan air dan es yang merupakan salah satu sumber kontaminasi bakteri Coliform. Minuman es teh dibuat menggunakan air masak $(85,7 \%)$ dan air galon (14,3\%). Proses memasak air selama 2-3 menit dengan suhu $100^{\circ} \mathrm{C}$ merupakan cara sederhana untuk membunuh seluruh bakteri, kecuali spora. Penggunaan air masak dapat mencegah kontaminasi bakteri Coliform pada minuman es teh. Faktor-faktor yang mempengaruhi kontaminasi bakteri Coliform pada minuman es teh adalah air yang digunakan untuk membuat es teh, es yang digunakan, air untuk mencuci gelas, dan kebersihan pembuat minuman es teh (Ariefiansyah. et al, 2015).

Tujuan penulisan dari penelitian ini adalah untuk Untuk mengetahui ada tidaknya pencemaran bakteri Coliform dan Colitinja pada minuman es teh yang dijual di Pelabuhan Rambang Kota Palangka Raya dan untuk mengetahui jumlah MPN (Most Probable Number) Coliform dan Colitinja pada minuman es teh yang dijual di Pelabuhan Rambang Kota Palangka Raya.

Manfaat penelitian ini adalah (1) untuk menambah dan memperluas pengetahuan tentang cemaran mikroba bakteri Coliform dan Colitinja pada minuman. (2) Untuk memberikan informasi kepada masyarakat agar lebih selektif untuk memilih jenis minuman yang aman untuk dikonsumsi. (3) Untuk memberikan informasi kepada pedagang agar lebih memperhatikan hygiene sanitasi dalam proses pengolahannya.

\section{METODE PENELITIAN}

\section{Waktu dan Tempat Penelitian}

Waktu pelaksanaan penelitian adalah terhitung dari bulan Mei sampai bulan Juni 2016. Pengambilan sampel dilakukan pada tanggal 07 Juni 2016. Pemeriksaan dan pengamatan sampel dilakukan di Laboratorium Mikrobiologi Fakultas IImu Kesehatan Universitas Muhammadiyah Palangkaraya. 


\section{Populasi dan Sampel}

Populasi dalam penelitian ini adalah minuman es teh yang dijual di Pelabuhan Rambang Kota Palangka Raya. Berdasarkan observasi awal penjual es teh di Pelabuhan Rambang Kota Palangka Raya sebanyak 6 penjual tetap. Sampel yang digunakan adalah es teh yang dibeli dari 6 penjual di Pelabuhan Rambang kota Palangka Ra

HASIL DAN PEMBAHASAN

Dari hasil penelitian yang telah dilakukan pada 6 sampel es teh yang dibeli dari enam pedagang es teh di Pelabuhan Rambang Kota Palangka Raya diperoleh hasil pada tabel berikut :

Tabel 1. Data Hasil Uji Praduga Pada Minuman Es Teh Dengan Media LBDS dan LBSS Pada Suhu $37^{\circ} \mathrm{C}$.

\begin{tabular}{|c|c|c|c|c|c|}
\hline \multirow{2}{*}{ No. } & \multirow{2}{*}{ Kode } & \multicolumn{3}{|c|}{ Hasil Uji Praduga } & \multirow{2}{*}{ Keterangan } \\
\hline & & $10 \mathrm{ml}$ & $1 \mathrm{ml}$ & $0,1 \mathrm{ml}$ & \\
\hline 1. & $\begin{array}{l}\text { Kontrol } \\
\text { Negatif }\end{array}$ & 0 & 0 & 0 & \multirow{7}{*}{$\begin{array}{c}\text { (+) Adanya kekeruhan } \\
\text { dan gelembung udara } \\
\text { didalam tabung } \\
\text { durham }\end{array}$} \\
\hline 2. & $A$ & 5 & 1 & 1 & \\
\hline 3. & B & 5 & 1 & 1 & \\
\hline 4. & C & 5 & 1 & 1 & \\
\hline 5. & $\mathrm{D}$ & 5 & 1 & 1 & \\
\hline 6. & $E$ & 5 & 1 & 1 & \\
\hline 7. & $\mathrm{~F}$ & 5 & 1 & 1 & \\
\hline
\end{tabular}

Sumber: Data Primer, 2016 
Pemeriksaan Mpn Coliform Dan Colitinja Pada Minuman Es Teh Yang Dijual Di Pelabuhan Rambang Kota Palangka Raya

Tabel 2. Data Hasil Uji Penegasan MPN Pada Minuman Es Teh Dengan Media BGLB Pada Suhu $37^{\circ} \mathrm{C}$.

\begin{tabular}{|c|c|c|c|c|c|c|}
\hline \multirow{2}{*}{ No. } & \multirow{2}{*}{ Kode } & \multicolumn{3}{|c|}{ Hasil Uji Praduga } & \multirow{2}{*}{$\begin{array}{c}\text { MPN/100 } \\
\mathrm{ml}\end{array}$} & \multirow{2}{*}{ Keterangan } \\
\hline & & $10 \mathrm{ml}$ & $1 \mathrm{ml}$ & $0,1 \mathrm{ml}$ & & \\
\hline 1. & $\begin{array}{l}\text { Kontrol } \\
\text { Negatif }\end{array}$ & 0 & 0 & 0 & - & \\
\hline 2. & $A$ & 5 & 1 & 1 & 240 & (+) Adanya \\
\hline 3. & B & 5 & 1 & 1 & 240 & $\begin{array}{l}\text { kekeruhan dan } \\
\text { gelembung udara }\end{array}$ \\
\hline 4. & C & 5 & 1 & 1 & 240 & $\begin{array}{c}\text { didalam tabung } \\
\text { durham }\end{array}$ \\
\hline 5. & $\mathrm{D}$ & 5 & 1 & 1 & 240 & \\
\hline 6. & $E$ & 5 & 1 & 1 & 240 & \\
\hline 7. & $\mathrm{~F}$ & 5 & 1 & 1 & 240 & \\
\hline
\end{tabular}

Sumber: Data Primer, 2016

Tabel 3. Data Hasil Uji Penegasan MPN Pada Minuman Es Teh Dengan Media BGLB Pada Suhu $44^{\circ} \mathrm{C}$.

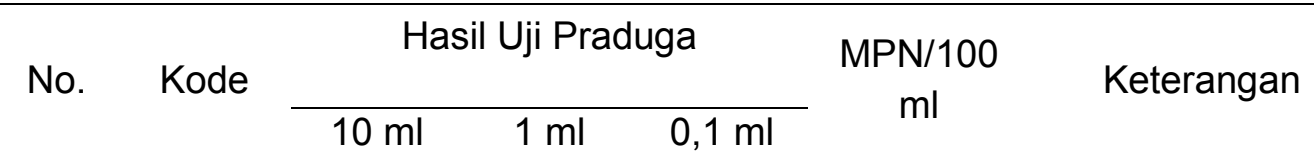

\begin{tabular}{|c|c|c|c|c|c|c|}
\hline 1. & $\begin{array}{l}\text { Kontrol } \\
\text { Negatif }\end{array}$ & 0 & 0 & 0 & - & \\
\hline 2. & A & 5 & 1 & 1 & 240 & \\
\hline 3. & B & 5 & 1 & 1 & 240 & $\begin{array}{c}(+) \text { Adanya } \\
\text { kekeruhan dan } \\
\text { gelembuna udara }\end{array}$ \\
\hline 4. & C & 5 & 1 & 1 & 240 & $\begin{array}{c}\text { didalam tabung } \\
\text { durham }\end{array}$ \\
\hline 5. & D & 5 & 1 & 1 & 240 & \\
\hline 6. & $E$ & 5 & 1 & 1 & 240 & \\
\hline 7. & $F$ & 5 & 1 & 1 & 240 & \\
\hline
\end{tabular}

Sumber: Data Primer, 2016 
Pada penelitian ini dilakukan pemeriksaan air minum yang bertujuan untuk mengetahui ada tidaknya pencemaran bakteri Coliform dan Colitinja Pada pemeriksaan kualitas air minum pada penelitian ini digunakan es teh sebagai sampel. Minuman es teh merupakan minuman yang digemari konsumen rumah makan karena harganya terjangkau dan dapat dijadikan pendamping makanan. Minuman es teh dibuat dengan menggunakan air dan es yang merupakan salah satu sumber kontaminasi bakteri Coliform. Minuman es teh adalah minuman umum yang banyak disukai masyarakat. Oleh karena itu perlunya diketahui apakah minuman es teh terkontaminasi/tercemar dengan melihat keberadaan bakteri Coliform dan Colitinja.

Penelitian pemeriksaan terhadap minuman es teh ini dilakukan uji mikro dengan metode MPN, metode MPN umumnya digunakan untuk menghitung jumlah bakteri khususnya untuk bakteri Coliform dan Colitinja. Bakteri Coliform merupakan suatu grup bakteri yang digunakan sebagai indikator adanya polusi kotoran dan kondisi sanitasi yang tidak baik terhadap air, makanan, susu dan produkproduk susu. Bakteri Colifrom merupakan indikator alami baik di dalam air yang tampak jernih maupun air kotor yang berasal dari tanah dan air itu sendiri, sedangkan bakteri Colitinja merupakan bakteri yang berasal dari saluran pencernaan manusia. Bakteri
Coliform bisa bertahan hidup pada suhu $37^{\circ} \mathrm{C}$ sedangkan Colitinja pada suhu $44^{\circ} \mathrm{C}$.

Dalam penelitian ini peneliti menggunakan kontrol media negatif dengan perlakuan tanpa menggunakan sampel. Tujuan digunakannya kontrol media negatif yaitu untuk memastikan bahwa kontrol media negatif tersebut tidak terkontaminasi bakteri, artinya hasil penelitian yang positif tercemar bakteri Coliform dan Colitinja itu benar-benar berasal dari sampel bukan dari media atau cara pengerjaannya.

Dalam metode MPN ini dilakukan beberapa tahap percobaan yaitu, pada tahap uji praduga (presumtive test) dan uji penegasan (confirmative test) untuk menegaskan hasil positif pada uji praduga. Uji praduga dalam penelitian ini dilakukan dengan menggunakan 7 tabung reaksi yang berisi sampel dan media LBDS dan LBSS untuk masing-masing sampel yang diinkubasi selama 24 jam pada suhu $37^{\circ} \mathrm{C}$, sedangkan untuk uji penegasan menggunakan hasil yang positif dari uji praduga dengan menginokulasi pada tabung BGLB dan diinkubasi pada suhu $37^{\circ} \mathrm{C}$ dan $44^{\circ} \mathrm{C}$ selama 24 jam.

Dari hasil penelitian yang dilakukan setelah melalui tahap uji praduga dan uji penegasan didapatkan hasil bahwa 6 sampel yang diteliti positif mengandung bakteri Coliform dan Colitinja, sampel yang positif bisa dilihat dari adanya kekeruhan dan gelembung gas pada tabung durham yang ada pada tabung reaksi. Didapatkan hasil 
positif dengan nilai MPN nya 240/100 ml. Hal ini menandakan bahwa 6 sampel minuman es teh yang diuji tidak layak untuk dikonsumsi oleh masyarakat karena menunjukkan hasil positif mengandung bakteri Coliform dan Colitinja, faktor yang mempengaruhi kontaminasi bakteri Coliform dan Colitinja pada minuman es teh adalah air yang digunakan untuk membuat es teh, dan es batu yang digunakan karena tidak diketahui apakah air yang digunakan adalah air bersih, air yang sudah dimasak atau bukan.

Terkontaminasinya air minum oleh Colitinja disebabkan karena sumber air tersebut letaknya dekat dengan pembuangan feses manusia atau air sungai. Untuk mencegah terjadinya kontaminasi ialah menggunakan sumber air bersih dan air tersebut sebaiknya terlebih dahulu dimasak sempurna dan disimpan ditempat yang bersih sebelum digunakan untuk membuat minuman jajanan.

Untuk mendapatkan es teh yang baik, aman dan terhindar dari pencemaran bakteri maka perlu diperhatikan kebersihan dan sanitasi saat proses pengolahan atau pembuatan minuman es teh. Karena air merupakan komponen terbesar dalam produk minuman dengan demikian perlu kecermatan dan pertimbangan yang matang dalam memilih jenis air yang sesuai untuk menghasilkan produk yang baik tidak terkecuali dalam hal menyeduh teh.

Standar baku Mutu Menteri Kesehatan Republik Indonesia nomor
492/MENKES/Per/IV/2010,

Tentang

Persyaratan Kualitas Air Minum, bahwa air untuk minum seharusnya tidak mengandung bakteri patogen dan kadar maksimum $E$. Coli pada air minum adalah $0 / 100 \mathrm{~mL}$ sampel. Maka sampel es teh yang telah diuji membuktikan bahwa sampel tersebut tidak aman untuk dikonsumsi masyarakat sesuai dengan

Kepmenkes

$\mathrm{RI}$ No.492/MENKES/PER/2010 tentang Persyaratan Kualitas Air Minum, karena positif (+) mengandung bakteri Coliform dan Colitinja.

\section{KESIMPULAN}

Berdasarkan hasil penelitian tentang "Pemeriksaan MPN Coliform dan Colitinja Pada Minuman Es Teh yang Dijual Di Pelabuhan Rambang Kota Palangka Raya" dapat ditarik kesimpulan bahwa Pemeriksaan dengan menggunakan metode MPN (Most Probable Number) pada es teh yang dijual di Pelabuhan Rambang Kota Palangka Raya positif terkontaminasi bakteri Coliform dan Colitinja. (2) Terdeteksi adanya kontaminasi bakteri Coliform dan Colitinja dalam minuman es teh yang dijual di Pelabuhan Rambang Kota Palangka Raya. Hal ini mengindikasikan terjadi pencemaran biologis dan menjadi dasar bahwa air minuman es teh tersebut berkualitas buruk serta dapat membahayakan masyarakat sebagai pengguna. (3) Jumlah MPN (Most Probable Number) Coliform dan Colitinja pada 6 sampel minuman es teh yang dijual di

] 
Pelabuhan Rambang Kota Palangka Raya adalah masing-masing 240/100 mL.

\section{DAFTAR PUSTAKA}

Ajisaka. 2012. Teh Dahsyat Khasiatnya. Surabaya: Stomata.

Anggraeni, Agustina. 2013. Identifikasi Pemanis Buatan Siklamat Pada Minuman Teh Yang Dijual Di Pelabuhan Rambang Palangka Raya. Palangkaraya: Fakultas IImu Kesehatan Universitas Muhammadiyah Palangkaraya.

Ariefiansyah, N. M., Suharti, N. dan Anas, E. 2015. Identifikasi BakteriColiform yang Terdapat pada Minuman Es Teh di Rumah Makan Tepi Laut Purus Padang Barat. Padang: Fakultas Kedokteran Universitas Andalas Padang.

Badwilan, S. A. 2010. Khasiat Teh. Surakarta: Thibbia.

Departemen Kesehatan Republik Indonesia. 1993. Pedoman Pelatihan Teknisi Laboratorioum Pemeriksaan Bakteriologis Air. Jakarta.

Departemen Kesehatan Republik Indonesia. 2003. Surat KeputusanMenteri Kesehatan Nomor 942/MENKES/SKVII/2003 Tentang Pesyaratan Hygiene Sanitasi Makanan Jajanan. Jakarta.

Departemen Kesehatan Republik Indonesia. 2009. Undang-Undang Republik Indonesia Nomor 36 Tahun 2009 tentang Kesehatan. Jakarta

Departemen Kesehatan Republik Indonesia. 2010. Surat Keputusan Menteri Kesehatan Nomor 492/Menkes/PER/IV/2010 Tentang
Persyaratan Kualitas Air Minum. Jakarta.

Bridson, E. Y. 1998. The Oxoid Manual.Compiled. Hal : 2-176, pdf. (sst-web. tees. ac. Uk /external /u 0003076 /Food_micro /oxoid manual. Pdf. Dalam Sunardi. 2014. Pemeriksaan Most Probable Number (MPN) BakteriColiform Dan Coli Tinja Pada Es teh Yang Dijual Di Pasar Besar Kota Palangkaraya. Palangkaraya: KTI Fakultas IImu Kesehatan Universitas Muhammadiyah Palangkaraya.

Fardiaz, Srikandi. 1992. Mikrobiologi Pangan I. Jakarta: Gramedia Pustaka Utama.

Gillespie, S. H. dan Kathleen, B. 2008. At a Glance Mikrobiologi Medis dan Infeksi, Edisi Ketiga. Jakarta: Erlangga.

Irianto, Koes. 2013. Mikrobiologi Medis. Bandung : Alfabeta.

Misnadiarly dan Djajaningrat, H. 2014. Mikrobiologi Untuk Klinik Dan Laboratorium. Jakarta: Rineka Cipta.

Notoadmodjo, Soekidjo. 2005. Metodologi Penelitian Kesehatan. Jakarta:Rineka Cipta.

Nugroho, A. 2006. Bioindikator Kualitas Air. Jakarta: Universitas Trisakti.

Rahayu, P. W. dan Nurwitri, C. C. 2012. Mikrobiologi Pangan. Bogor: IPB Press.

Rossi, A. 2010. Dari Asal Usul, Tradisi, Khasiat, Hingga Racikan Teh. Yogyakarta: CV. Andi

Sugiyono, 2015. Metode Penelitian Kuantitatif Kualitatif dan R\&D. Bandung: Alfabeta, CV.

Tarwodjo, C. S. 1998. Dasar-Dasar Gizi Kulier. PT. Gramedia : Jakarta. 
